\title{
Infinity Period Dynamic Control of a Kind of Channel's Price and Brand Investment: A Differential Game Method
}

\author{
Kaihong Wang, ${ }^{1}$ Li Cheng, ${ }^{2}$ and Chuan Ding ${ }^{1}$ \\ ${ }^{1}$ School of Economic Mathematics, Southwestern University of Finance and Economics, Chengdu 610074, China \\ ${ }^{2}$ Research Center for Social Work Development, Southwestern University of Finance and Economics, Chengdu 610074, China
}

Correspondence should be addressed to Kaihong Wang; wangkaihong@swufe.edu.cn

Received 22 November 2014; Accepted 20 January 2015

Academic Editor: Honglei Xu

Copyright (C) 2015 Kaihong Wang et al. This is an open access article distributed under the Creative Commons Attribution License, which permits unrestricted use, distribution, and reproduction in any medium, provided the original work is properly cited.

\begin{abstract}
The infinity period dynamic control problem of distribution channel was studied with differential game approach. Four differential dynamic control models of coordinated channel game, uncoordinated static game, Stackelberg game with manufacture controlled, and Stackelberg game with $n$ retailers controlled were constructed. Some results applied dynamic optimization theory made with Hamilton function. The conclusions are as follows. (1) Optimization brand investment controlled by manufacture has nothing to do with time. (2) Retail price was the most minimum when channel was integrated. (3) Manufacture's profits of uncoordinated static game and Stackelberg game with manufacture controlled were more than Stackelberg game with $n$ retailers controlled. (4) Retailer's profits of Stackelberg game with $n$ retailers controlled were less than Stackelberg game with manufacture controlled. (5) Channel's total profits of Stackelberg game with $n$ retailers controlled were the most minimum.
\end{abstract}

\section{Literature Review and Research Purpose}

1.1. Literature Review. Channel members of distribution channel have different target; the channel conflict is likely to happen; therefore, we cannot achieve the pareto optimal decision without channel coordination mechanism. Whether channel manufacturer should vertically integrate (coordination) the manufacturer or sell products by ordinary manufacturer have become the center of attention. Distribution channel decision is mainly focused on two aspects. The first aspect mainly is an analysis of five kinds of channel structure by some marketing experts, on behalf of Desiraju and Moorthy [1] (as shown in Figure 1); the second aspect mainly is channel coordination problem, whose research has a long history. Baligh and Richartz argued that channels should be integrated to achieve internal coordination [2]. But there are some deficiencies in their research, one is not considering the market power of manufacturers and intermediaries, another is ignoring the product differentiation or substitution degree.

In particular, after being searched by McGuire and Staelin [3], channel competition and coordination have become the focus. Jeul and Shugan [4] had researched a question about channel coordination consisting of one manufacturer and a retailer. They considered that, except incentive channel members properly, coordination could become their instinctive behavior. Simultaneously, vertical integration was not the only way to maximize channel profit, which could also come true by agreement, channel latent rules, profit sharing, and quality discount to realize coordination. McGuire and Staelin [3] considered that channel consisted of manufacturer and competitive retailers, and both of them could attend Stackelberg leading game. At this time, vertical integration is not optimal. However, McGuire and Staelin [3] still did not consider the problem of differentiated product. Coughlan [5] researched the issue of vertical integration differentiated product oligarch market, choosing the product price and market channel to maximize the profit; vertical integration had more competitive advantages in price than independent management of members. They also achieved some empirical in semiconductor industry. $\mathrm{Xu}$ et al. [6] proposed both single contracts and joint contracts to achieve coordination; they found that the coordinating revenue sharing contract and two-part tariff contract in the supply chain with risk neutral agents were still useful to coordinate the supply chain 


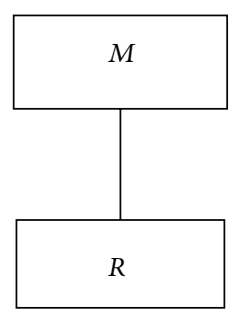

(a)

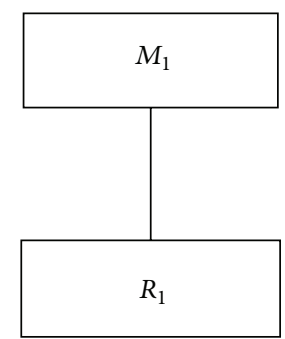

(d)

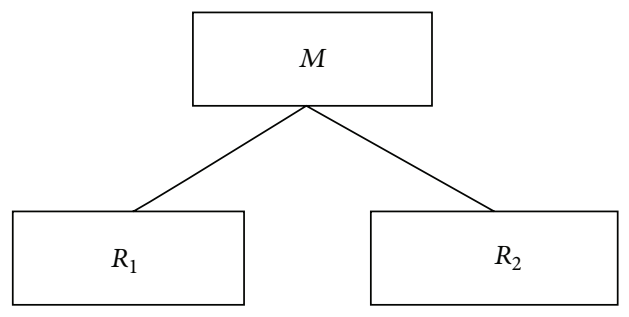

(c)

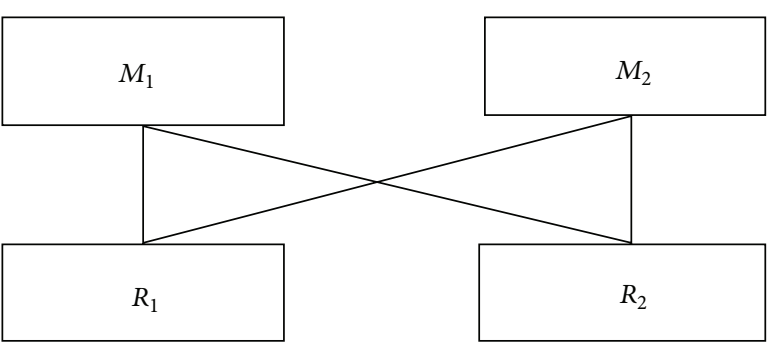

(e)

FIGURE 1: Five channel structures.

taking into account the degree of risk aversion of fashion retailer. They demonstrated that only revenue sharing with two-part tariff contract could coordinate the fashion supply chain. The optimal conditions for contract parameters to achieve channel coordination were determined. Ding et al. [7] constructed four models based on different range of the result fairness preference's coefficient. They thought if there was no coordination mechanism, then the channel coordination could not be achieved in both types (the narrow self-interest and the competitive preference). And channel coordination could be achieved in the types of the avoiding unfair preference and the social welfare preferences, when a fair preference coefficient and other parameters satisfied certain conditions. Ding et al. [8] presented a quantity discount mechanism based on a result fairness preference for achieving channel coordination. They thought that as long as the degree of attention of retailer to manufacturer's profit and the fairness preference coefficients of retailers satisfied certain conditions, channel coordination could be achieved by setting a simple wholesale price and fixed costs. Ding et al. [9] adopted a behavior game method to analyze and forecast channel members' decision behavior based on result fairness preference and reciprocal fairness preference by embedding a fair preference theory in channel research of coordination.

The researches above were mainly about the channel of one manufacturer with one or several middlemen and did not mention the channel of several manufacturers with one retailer, not to speak of channel with various manufacturers and retailers. Altintas et al. [10] studied a multiperiod model, with a buyer facing stochastic end-item demand and a supplier offering an all-units quantity discount to them, studied the supplier's profit as a function of their offered quantity-discount scheme (accommodating the buyer's optimal policy), and discovered a new phenomenon that was distinct and structurally different from the well-known bullwhip effect. Song et al. [11] examined the effect of market segments, consumer choice, and the acceptance of direct online channels on firm performance and the whole system's profit. The analysis indicated that the addition of direct online channel did not necessarily harm the incumbent retailers. A channel coordination zone was proposed. Wang et al. [12] presented a useful and practical procurement approach using the joint replenishment and channel coordination (JRCC) policy in a two-echelon supply chain considering the coordination cost.

But these studies were mainly static decision of channel members; some scholars had studied the channel members' decision from the dynamic perspective. For example, Zhao et al. [13] assumed that coordination could increase the sales by accumulating the reputation of the supply chain. A differential game model was established with the logistics service supply chain that consists of one service integrator and one supplier. And the results made the benefits of the cost sharing contract in increasing the profits of both players and the whole supply chain explicit, which meant that the cost sharing contract was an effective coordination mechanism in the long-term relationship of the members in a logistics service supply chain. Li et al. [14] considered a decentralized two-period supply chain in which a manufacturer produced a product and sold it through a retailer facing a pricedependent demand. They obtained revenue sharing contracts that could coordinate the dynamic supply chain.

In practice, the channel member may be loss-averse; Chen et al. [15] studied channel coordination with a lossaverse retailer that orders from a risk-neutral supplier via option contracts. This study considered sales-effort dependent demand to extend the model of Wang and Webster [16]. In this area, there were many rich results; due to limited space, we omitted these results and mainly focused 
on the multiperiod dynamic channel decision. Jiang et al. [17] investigated decision and coordination in a supplychain-wide system consisting of a manufacturer, a third-party logistics (3PL) provider, and two competing retailers. They discussed the dominant retailer model where one retailer was a price leader, and the other was a price follower, three contracts: a spanning revenue sharing contract, a quantity discount contract and a two-part tariffs contract were devised to effectively coordinate the decentralized system involving the 3PL provider. Yin et al. [18] considered one manufacturer and multiple suppliers to determine production, prices, and inventory simultaneously with uncertain demands, they aimed at providing an optimal discount policy derived from Stackelberg equilibrium to coordinate a manufacturer and multiple suppliers. The optimal discount coordination mechanism helps the manufacturer to select suppliers in order to maintain long-term relationship with the contracted suppliers under demand uncertainty.

The above researches were based on symmetric information, from the perspective of asymmetric information; Rajiv [19] regarded that coordination level could be improved through channel franchise arrangement. He researched products distribution of manufacturers by service and price of middlemen and considered that member coordination could not be improved by controlling and ascendancy of channel members. Benjamin and Tracy [20] thought that demand condition was the private information of middlemen, who would be in push of sale by promotion. But effort level was also the private information which was not easy to be observed. And manufacturer was also unaware that whether sales volume was associated with the effort level of middlemen. Moral risk model was built based on the information asymmetry. Zissis et al. [21] derived analytical expressions of the quantity discounts that minimize the manufacturer's costs when the retailer had private information. Furthermore, they showed that perfect coordination was possible even under asymmetric information. The results showed that retail competition contributes to manufacturer and improves channel efficiency of the decentralized supply chain. When the retailers were more risk averse, the channel efficiency becomes much lower. Luo et al. [22] researched decentralized supply chain incentive mechanism, which was actually selling race. Tian et al. [23] analyzed with two manufacturers and a retailer of principal-agent problems in the distribution system. In this system, two manufacturers were principal and retailers were agent; the results showed that the manufacturers in noncoordinative competition were damaged, especially the damage to manufacturers was higher with the substitution of their products increasing, and the retailer was benefited more in the situation. Chen et al. [24] studied from the perspective of distribution channel alliance coordination, discussed the formation mechanism of distribution channel alliance interests, and put forward the mechanism of subsidy income change of the game. When manufacturers did not know distributors type, if marketing alliance was unprofitable to manufacturers, they would not choose channel alliance. If its profits would be improved, they were willing to enter into alliance with the distributor.
1.2. Research Purpose. In Section 1.1, we reviewed the research status from the two dimensions (the number of channel members and whether the information was symmetrical or not). However, these studies had two defects.

First, it was a pity that these studies were single stage decision of the channel member, or a static decision. In fact, we found that the current sales were affected by the current sales decisions and also affected by the channel members of past marketing decisions. For example, the manufacturer brand advertising will affect the sales of the product for a long time and has a cumulative effect to the manufacturer's product reputation (goodwill). So this was a long-term dynamic relationship; it needs be studied with a "control theory" and "differential game."

Second, Pradeep and Jain [25], Jørgensen and Zaccour [26], Martín-Herrán and Taboubi [27], and Martín-Herrán and Taboubi [28] used this theory to study simple channels (in Figure 1(a)). Martín-Herrán and Taboubi [29] studied in Figure 1(b) with this theory. In practice, the manufacturer's products through a number of retailers to sell to consumers; therefore, in Figure 1(c) is a common channel structure. We need to study this channel structure (Figure 1(c)) from the perspective of long-term dynamic.

In this paper, according to the two defects, we used the theory of "control" and "differential game" to study another distribution channel structure (Figure 1(c)) - a manufacturer and $n$ retailers. Our researches showed that (1) optimization brand investment controlled by manufacture has nothing to do with time. (2) Retail price was the most minimum when channel was integrated. (3) Manufacture's profits of uncoordinated static game and Stackelberg game with manufacture controlled were more than Stackelberg game with $n$ retailers controlled. (4) Retailer's profits of Stackelberg game with $n$ retailers controlled were less than Stackelberg game with manufacture controlled. (5) Channel's total profits of Stackelberg game with $n$ retailers controlled were the most minimum.

\section{Symbols, Concepts, and Basic Assumptions}

Due to the competition of the market, the layer number of channels is decreasing gradually and many industry patterns distribute products by the pattern of manufacturers-retailerscustomers. So in this paper, the channel system is made up of manufacturers, retailers, and customers and is threelevel distribution channel management system, so this paper focuses on the simple channel system of manufacturers and retailers.

For convenience analysis, we give the following symbols, assumptions, and a brief illustration of some concept.

Assumptions 1. Channel consists of a manufacturer and $n$ retailers.

Assumptions 2. Time $t \in[0,+\infty)$; manufacturer controls the marginal profits $m_{M}(t)$ and brand investment $B_{M}(t)$ (such as advertising, public relations, effort, etc.), retailers control their margins profit $m_{i}(t)$ as well as investment $B_{i}(t)$ in order to increase sales (such as in-store promotions and sales 
efforts, etc.), $i=1,2, \ldots, n$. The retail price of retailer $p_{i}(t)$ is the sum of the marginal profits of manufacturer $m_{M}(t)$ and marginal profit of retailers $m_{i}(t)$. Consider

$$
p_{i}(t)=m_{M}(t)+m_{i}(t), \quad i=1,2, \ldots, n .
$$

Assumptions 3. Market demand function for retailers is [26, 27]

$$
q_{i}(t)=B_{i}(t)\left[a-b p_{i}(t)\right] \sqrt{G(t)} .
$$

$a>0, b>0$ is constant and $i=1,2, \ldots, n, G(t)$ is the stock of band goodwill of products at time $t \in[0,+\infty)$. In this paper, we use $q_{i}(t)=B_{i}(t)\left[a-b p_{i}(t)\right] \sqrt{G(t)}$, which reflects the retailer's market demand which is proportional to the sales of their investment $B_{i}(t)$, and the price $p_{i}(t)$ and demand response and reputation have the same direction change. $\sqrt{G(t)}$ indicate that reputation $G(t)$ is diminishing to demand and also suggests that retailers are only concerned with the present demand. In time $t, t \in[0,+\infty)$, his marketing investment $m_{i}(t)$ affects only sales at time $t, t \in[0,+\infty)$ and does not affect the reputation of products. And manufacturer is more concerned about the reputation of the brand, so brand investment of manufacturer $B_{M}(t)$ does not directly affect demand; by reputation $G(t)$ indirectly affects demand.

Assumptions 4. From the Assumptions 3, manufacturer's brand investment $B_{M}(t)$ affects the demand by reputation $G(t)$ indirectly, and reputation $G(t)$ has the characteristic of natural attenuation. Let it according to the index law decay over time, as $e^{-\delta t}$ attenuation, in which $\delta$ is the attenuation coefficient, so the change of the reputation can be described by the Nerlove-Arrow equation:

$$
\frac{d G(t)}{d t}=B_{M}(t)-\delta G(t), \quad G(0)=G_{0}>0
$$

Assumptions 5. In practice, cost function needs to meet the marginal cost increases; according to references [25-29], we assume that the cost of manufacturer's brand investment is $(1 / 2) c_{M} B_{M}(t)^{2}$. The investment costs of retailers $B_{i}(t)$ are $(1 / 2) c_{i} B_{i}(t)^{2}, i=1,2, \ldots, n$. Because the cost of different channel members is not same, the cost functions $c_{M}, c_{i}(i=$ $1,2, \ldots, n)$ are also not identical. Square cost function in the form guarantees that the first-order conditions are greater than zero and the second order condition is greater than zero.

\section{Manufacturer Integration (Shorthand for $T$ ) Distribution Channel}

In channel, manufacturer can integrate the whole channel to get more channel profit, so this section analyzes manufacturer integrated situation and the latter analyzes noncoordination game.
According to the previous assumptions and (1), (2), and (3), manufacturer's discount profits in time $t, t \in[0,+\infty)$ are

$$
\begin{aligned}
\pi_{M}=\int_{0}^{+\infty} & e^{-r t} m_{M}(t) \sum_{i=1}^{n}\left[B_{i}(t)\left(a-b p_{i}(t)\right) \sqrt{G(t)}\right] \\
& -\frac{1}{2} c_{M} B_{M}(t)^{2} d t .
\end{aligned}
$$

At $t, t \in[0,+\infty)$, retailer $i$ 's all discount profits is as follows:

$$
\begin{gathered}
\pi_{i}=\int_{0}^{+\infty} e^{-r t} m_{i}(t) \sum_{i=1}^{n}\left[B_{i}(t)\left(a-b p_{i}(t)\right) \sqrt{G(t)}\right] \\
-\frac{1}{2} c_{i} B_{i}(t)^{2} d t, \quad i=1,2, \ldots, n,
\end{gathered}
$$

where in (4)-(5) $e^{-r t}$ and $r$ are the discount factor and discount rate, respectively.

If the channel needs to be integrated, different scholars have different ways of integration. This paper comes to a manufacturer and $n$ retailers. So manufacturer and retailers adopt integration marginal profit as follows: $m^{i}(t)=m_{M}(t)+$ $m_{i}(t), i=1,2, \ldots, n$. The integrated decision variables are $m^{i}(t), B_{M}(t), B_{i}(t)$. So we get the total channel profit after integration:

$$
\begin{aligned}
\pi^{T}=\int_{0}^{+\infty} & e^{-r t} \sum_{i=1}^{n} m^{i}(t)\left[B_{i}(t)\left(a-b p_{i}(t)\right) \sqrt{G(t)}\right] \\
& -\frac{1}{2} \sum_{i=1}^{n} c_{i} B_{i}(t)^{2} d t .
\end{aligned}
$$

Because the margin profit $m^{i}(t)$ and $B_{i}(t)$ is not in the dynamic equation (3), so, in (6), two first-order conditions about $m^{i}(t)$ and $B_{i}(t)$, respectively, are

$$
\begin{array}{r}
\frac{\partial \pi^{T}}{\partial m^{i}(t)}=a-2 b m^{i}(t)=0, \quad i=1,2, \ldots, n, \\
\frac{\partial \pi^{T}}{\partial B^{i}(t)}=m^{i}(t)\left(a-b m^{i}(t)\right) \sqrt{G(t)}-c_{i} B_{i}(t)=0, \\
i=1,2, \ldots, n .
\end{array}
$$

Due to the symmetry (7), we can get

$$
m^{i}(t)=\frac{a}{2 b}, \quad i=1,2, \ldots, n .
$$

Equation (9) is taken into (8):

$$
B_{i}^{T *}=\frac{a^{2}}{4 b c_{i}} \sqrt{G^{T *}(t)}, \quad i=1,2, \ldots, n .
$$

To achieve maximum value of (6), we also need the firstorder conditions about $B_{M}(t)$ in (6). Because $B_{M}(t)$ is implicity in $G(t)$, we can not derive the partial derivatives directly. Due to the particularity of the integral, we need integral firstly 
and then derive partial derivatives. The following is to find out optimal $B_{M}^{T *}(t)$.

At present, the theory methods have two kinds. One is to construct Hamilton-Jacobi-Bellman (HJB) equation. Another is to construct the Hamilton function. In the paper, we construct the Hamilton function to solve the optimal $B_{M}^{T *}(t)$ (see [28-31]).

Now we build the present value Hamilton function to find the optimal $B_{M}^{T *}(t)$. According to [28-32], the present value of the Hamilton function in (6) is

$$
\begin{aligned}
H_{C}^{T}= & \sum_{i=1}^{n} m^{i}(t) B_{i}(t)\left(a-b p_{i}(t)\right) \sqrt{G(t)} \\
& -\frac{1}{2} \sum_{i=1}^{n} c_{i} B_{i}(t)^{2}+\lambda\left[B_{M}(t)-\delta G(t)\right] .
\end{aligned}
$$

So the fixed present value Hamilton functions is

$$
\begin{gathered}
H^{T}=\sum_{i=1}^{n} m^{i}(t)\left(B_{i}(t)\left(a-b p_{i}(t)\right) \sqrt{G(t)}\right) \\
\quad-\frac{1}{2} \sum_{i=1}^{n} c_{i} B_{i}(t)^{2}+h\left[B_{M}(t)-G(t)\right] . \\
h=\lambda e^{r t} ; \text { put (9) and (10) into (12): } \\
H_{C}^{T}=\sum_{i=1}^{n} \frac{a^{4}}{32 b^{2} c_{i}} G^{T *}-\frac{1}{2} c_{M} B_{M}(t)^{2}+h\left[B_{M}(t)-\delta G(t)\right] .
\end{gathered}
$$

According to the principle of the modified maximum. There are the following necessary conditions for optimal solution.

(1) State equation and the initial conditions:

$$
\frac{d G(t)}{d t}=B_{M}(t)-\delta G(t), \quad G(0)=G_{0}>0
$$

(2) Multiplier equation:

$$
\frac{\partial h}{\partial t}=r h-\frac{\partial H^{T}}{\partial G}=r h+h \delta-\sum_{i=1}^{n} \frac{a^{4}}{32 b^{2} c_{i}} .
$$

(3) The optimal equation:

$$
\frac{\partial H^{T}}{\partial t}=-c_{M} B_{M}(t)+h=0 .
$$

(4) Cross-sectional conditions:

$$
h(+\infty) e^{-r \infty}=\lambda(+\infty)=0 .
$$

Jointing (14), (15), (16), and (17), we may calculate $B_{M}^{T *}(t)$, $G^{T *}(t)$. Through the analysis of the above, we get Proposition 1 .
Proposition 1. In the integration of distribution channel, the optimal margins profit, the manufacturer's optimal brand investments, sales of the optimal investment, and optimal reputation are, respectively,

$$
\begin{gathered}
m^{i}(t)=\frac{a}{2 b}, \quad i=1,2, \ldots, n, \\
B_{i}^{T *}(t)=\frac{a^{2}}{4 b c_{i}} \sqrt{G^{T *}(t)}, \quad i=1,2, \ldots, n, \\
B_{M}^{T *}(t)=\sum_{i=1}^{n} \frac{a^{4}}{32 b^{2}(r+\delta) c_{M} c_{i}}, \\
G^{T *}(t)=\left[G_{0}-\sum_{i=1}^{n} \frac{a^{4}}{32 b^{2}(r+\delta) \delta c_{M} c_{i}}\right] e^{-\delta t} \\
+\sum_{i=1}^{n} \frac{a^{4}}{32 b^{2}(r+\delta) \delta c_{M} c_{i}} .
\end{gathered}
$$

From Proposition 1, we find that the reputation of products has nothing to do with the integrated optimal marginal profit and the time. The retailer's marketing investment increases as the increasing of product reputation, but the speed of increase is more and more small. Manufacturer's brand investment has nothing to do with the time. The reputation in (19) will be compared later.

\section{The Analysis of the Multistage Dynamic Noncooperative Game about the Distribution Channel between Manufacturers and Retailers}

In the previous section, we analyze the channel coordination. The following is the analysis of the noncoordination. In practice, for channel members, the relation of dynamic noncoordination is more common. There are static game (shorthand for $N$ ), Stackelberg game led by manufacturers (shorthand for MS), and Stackelberg game led by retailers (shorthand for RS). Now, analyze, respectively, as follows.

4.1. The Analysis of the Static Multistage Game between Manufacturer and Retailers. In this channel relationship, manufacturer and $n$ retailers make their decisions at the same time, for maximizing their own profits. Therefore, we only need to find the first-order conditions of (4) and (5), respectively. Similar to the previous section, we analyze $m_{M}(t), m_{i}(t)$, and $B_{i}(t)$; they do not appear in the dynamic state equation (3), so, in (4), the first-order condition about $m_{M}(t)$ is

$$
\frac{\partial \pi_{M}}{\partial m_{M}(t)}=\sum_{i=1}^{n}\left[B_{i}(t)\left(a-2 b m_{M}(t)-b m_{i}(t)\right)\right]=0 .
$$

And the solution is

$$
m_{M}^{N *}(t)=\frac{a \sum_{i=1}^{n} B_{i}(t)-b \sum_{i=1}^{n} B_{i}(t) m_{i}(t)}{2 b \sum_{i=1}^{n} B_{i}(t)} .
$$


Similarly, in (5), the first-order condition about $m_{i}(t)$, $B_{i}(t)$ is

$$
\begin{array}{r}
\frac{\partial \pi_{i}}{\partial m_{i}(t)}=a-2 b m_{i}(t)-b M_{i}(t)=0, \\
i=1,2, \ldots, n, \\
\frac{\partial \pi_{i}}{\partial B_{i}(t)}=m_{i}(t)\left[a-b p_{i}(t)\right] \sqrt{G(t)}-c_{i} B_{i}(t)=0, \\
i=1,2, \ldots, n .
\end{array}
$$

Substituting (21) into (22):

$$
\begin{array}{r}
a \sum_{i=1}^{n} B_{i}(t)-4 b m_{i}(t) \sum_{i=1}^{n} B_{i}(t)+b \sum_{i=1}^{n} B_{i}(t) m_{i}(t)=0 \\
i=1,2, \ldots, n .
\end{array}
$$

The optimal solution is $m_{i}^{N *}(t)=m_{M}^{N *}(t)=a / 3 b$; thus the solution of (23) is

$$
B_{i}^{N *}(t)=\frac{a^{2}}{9 b c_{i}} \sqrt{G(t)}, \quad i=1,2, \ldots, n
$$

Then we construct Hamilton function for the best $B_{M}^{N *}$. The Hamiltonian function of (4) is

$$
\begin{aligned}
H^{N}= & G(t) \sum_{i=1}^{n} \frac{a^{4}}{81 b^{2} c_{i}}-\frac{1}{2} c_{M} B_{M}(t)^{2} \\
& +\lambda\left[B_{M}(t)-\delta G(t)\right] .
\end{aligned}
$$

With the method of Section 2, $B_{M}^{N *}, G^{N *}(t)$ can be obtained as follows. (To avoid duplication, details are omitted; please refer to $[26-28,30])$.

So the optimal solution meets the necessary conditions:

$$
\begin{gathered}
B_{M}^{N *}=\sum_{i=1}^{n} \frac{a^{4}}{81 b^{2}(r+\delta) c_{M} c_{i}}, \\
G^{N *} t=\left(G_{0}-\sum_{i=1}^{n} \frac{a^{4}}{81 b^{2}(r+\delta) c_{M} c_{i}}\right) e^{-\delta t} \\
+\sum_{i=1}^{n} \frac{a^{4}}{81 b^{2}(r+\delta) c_{M} c_{i}} .
\end{gathered}
$$

So, there is Proposition 2.

Proposition 2. In the distribution channel, when channel members make decisions at the same time, the best margins profits, manufacturer's best brand investments, retailers' bestselling investments, and the best reputation are, respectively,

$$
\begin{gathered}
m_{i}^{N *}(t)=m_{M}^{N *}(t)=\frac{a}{3 b}, \quad i=1,2, \ldots, n, \\
B_{i}^{N *}(t)=\frac{a^{2}}{9 b c_{i}} \sqrt{G(t)}, \quad i=1,2, \ldots, n, \\
B_{M}^{N *}=\sum_{i=1}^{n} \frac{a^{4}}{81 b^{2}(r+\delta) c_{M} c_{i}}, \\
G^{N *}(t)=\left(G_{0}-\sum_{i=1}^{n} \frac{a^{4}}{81 b^{2}(r+\delta) c_{M} c_{i}}\right) e^{-\delta t} \\
+\sum_{i=1}^{n} \frac{a^{4}}{81 b^{2}(r+\delta) c_{M} c_{i}} .
\end{gathered}
$$

4.2. The Multistage Game Analysis of Stackelberg Game Led by Manufacturers (Shorthand for MS). In practice, manufacturer may be in a dominant position, such as GREE electric appliances and Sony. This kind of game relation is the Stackelberg game manufacturer dominated. Manufacturer decides first and retailers then carry on the optimal decision according to manufacturer's choice. By backward induction, we find the subgame perfect Nash equilibrium.

In the second phase, the retailers make optimal decision. And in (5), the first-order condition is (22) and (23). So from (22) and (23) we can obtain the two reaction functions about $m_{i}(t), B_{i}(t), i=1,2, \ldots, n$ :

$$
\begin{gathered}
m_{i}(t)=\frac{a-b m_{M}(t)}{2 b}, \quad i=1,2, \ldots, n, \\
B_{i}(t)=\frac{\left(a-b m_{M}(t)\right)^{2}}{4 b c_{i}} \sqrt{G(t)}, \quad i=1,2, \ldots, n .
\end{gathered}
$$

Back to the first stage of the game, substituting (32) into the manufacturer's profit function,

$$
\begin{aligned}
\pi_{M}=\int_{0}^{+\infty} & e^{-r t} m_{M}(t)\left(a-b m_{M}(t)\right)^{3} G(t) \sum_{i=1}^{n} \frac{1}{8 b c_{i}} \\
& -\frac{1}{2} c_{M} B_{M}(t)^{2} d t .
\end{aligned}
$$

And the first-order condition about $m_{M}(t)$ is $m_{M}^{\mathrm{MS} *}(t)=$ $a / 4 b$. For (33), the first-order condition is $m_{M}^{\mathrm{MS}}(t)=a / 4 b$; we also construct Hamilton function $[19,20]$ :

$$
\begin{aligned}
H^{\mathrm{MS}}= & \frac{27 a^{4}}{2048 b^{2}} G(t) \sum_{i=1}^{n} \frac{1}{c_{i}}-\frac{1}{2} c_{M} B_{M}(t)^{2} \\
& +\lambda\left[B_{M}(t)-\delta G(t)\right] .
\end{aligned}
$$


Then, the best $m_{M}^{\mathrm{MS} *}(t)$ and $G^{\mathrm{MS} *}(t)$ are

$$
\begin{gathered}
B_{M}^{\mathrm{MS} *}(t)=\sum_{i=1}^{n} \frac{27 a^{4}}{2048 b^{2}(r+\delta) c_{M} c_{i}}, \\
G^{\mathrm{MS} *} t=\left(G_{0}-\sum_{i=1}^{n} \frac{27 a^{4}}{2048 b^{2}(r+\delta) \delta c_{M} c_{i}}\right) e^{-\delta t} \\
+\sum_{i=1}^{n} \frac{27 a^{4}}{2048 b^{2}(r+\delta) \delta c_{M} c_{i}} .
\end{gathered}
$$

And there is the following Proposition 3.

Proposition 3. In the Stackelberg game with manufacture dominated, the best margins profit, manufacturer's best brand investments, retailers' best-selling investments, and the best reputation are, respectively (the subgame perfect Nash equilibrium),

$$
\begin{gathered}
m_{M}^{M S *}(t)=\frac{a}{4 b}, \quad m_{i}^{M S *}(t)=\frac{3 a}{8 b}, \quad i=1,2, \ldots, n, \\
B_{i}^{M S *}(t)=\sum_{i=1}^{n} \frac{9 a^{2}}{64 b c_{i}} \sqrt{G^{M S *}(t)} \\
B_{M}^{M S *}=\sum_{i=1}^{n} \frac{27 a^{4}}{2048 b^{2}(r+\delta) c_{M} c_{i}}, \\
G^{M S *}(t)=\left(G_{0}-\sum_{i=1}^{n} \frac{27 a^{4}}{2048 b^{2}(r+\delta) \delta c_{M} c_{i}}\right) e^{-\delta t} \\
+\sum_{i=1}^{n} \frac{27 a^{4}}{2048 b^{2}(r+\delta) \delta c_{M} c_{i}} .
\end{gathered}
$$

4.3. The Multistage Game Analysis of the Stackelberg Game Led by Retailers (Shorthand for RS). In Section 4.2, we analyzed the Stackelberg game led by manufacturer. In reality, some major retailers control channels, especially some major retail stores which quickly fill the city and have strong bargaining power. So the research of Stackelberg game dominated by retailer has a practical significance.

Although they are two different game models, the analysis is consistent; in the first stage of the game, $n$ retailers choose their optimal marginal profit and optimal marketing investment according to the profit function. And in the second stage, manufacturer determines the optimal margins profit and the optimal brand investment. Similar to Section 4.2 , we can find the subgame perfect Nash equilibrium of the Stackelberg game led by retailers, which is given by Proposition 4.

Proposition 4. In the Stackelberg game retailers dominate; the best margins profit, manufacturers' best brand investments, retailers' best-selling investments, and the best reputation are, respectively (the subgame perfect Nash equilibrium),

$$
\begin{gathered}
m_{M}^{r S *}(t)=\frac{a}{4 b}, \quad m_{i}^{R S *}(t)=\frac{a}{2 b}, \quad i=1,2, \ldots, n, \\
B_{i}^{r S *}(t)=\sum_{i=1}^{n} \frac{a^{2}}{8 b c_{i}} \sqrt{G^{R S *}(t)} \\
B_{M}^{R S *}=\sum_{i=1}^{n} \frac{a^{4}}{128 b^{2}(r+\delta) c_{M} c_{i}}, \\
G^{R S *}(t)=\left(G_{0}-\sum_{i=1}^{n} \frac{a^{4}}{128 b^{2}(r+\delta) \delta c_{M} c_{i}}\right) e^{-\delta t} \\
+\sum_{i=1}^{n} \frac{a^{4}}{128 b^{2}(r+\delta) \delta c_{M} c_{i}} .
\end{gathered}
$$

\section{Comparative Analysis of Four Types of Game Model and Its Results}

In the previous Sections 2, 3, and 4, we have analyzed four game types. And in this section, we care about the result and comparative static analysis mainly from the perspective of consumers, manufacturers, and retailers. For consumers, we only consider retail price. For manufacturer and retailers, we need to analyze their margins profit, manufacturer's brand investments, reputation, retailers' sales investment, and the changes with time.

5.1. Comparative Analysis of Optimal Decision of Channel Members. For the retail prices, according to Assumptions $2, p_{i}(t)=m_{M}(t)+m_{i}(t), i=1,2, \ldots, n ;(9),(28),(36)$, and (40) are substituted, respectively,

$$
\begin{aligned}
& p_{i}^{T *}(t)=\frac{a}{2 b}, p_{i}^{N *}(t)=\frac{2 a}{3 b}, \\
& p_{i}^{\mathrm{MS} *}(t)=\frac{5 a}{8 b}, p_{i}^{\mathrm{RS} *}(t)=\frac{3 a}{4 b}, \\
& i=1,2, \ldots, n .
\end{aligned}
$$

So for a customer, there is the following Conclusion 1.

Conclusion 1. Among the coordination game, the noncoordination static game, Stackelberg game led by manufacturer, and Stackelberg game led by $n$ retailers, the best sale price meets

$$
p_{i}^{\mathrm{RS} *}(t)>p_{i}^{N *}(t)>p_{i}^{\mathrm{MS} *}(t)>p_{i}^{T *}(t), \quad i=1,2, \ldots, n .
$$

Conclusion 1 shows that for consumers, they want channel integration, or channel partners, because the price is the lowest, which coincide with the practice. When $n$ retailers dominate the channels, the retailers have the right to speak and they will set a higher retail price to gain more profit.

Then we analyze the relationship between the manufacturer's optimal decisions. The margins profit in coordinative 
game cannot be separated, so we only compare the rest. From (28), (36), and (40), there is Conclusion 2 clearly.

Conclusion 2. Among the noncoordination static game, Stackelberg game led by manufacturer, and Stackelberg game led by $n$ retailers, the manufacturer's optimal profit margins meet

$$
m_{M}^{\mathrm{RS} *}(t)<m_{M}^{N *}(t)<m_{M}^{\mathrm{MS} *}(t) .
$$

It can be seen from this relationship that the manufacturer has a definite right to speak when it is a leading enterprise, and it will naturally increase its margins profit in order to obtain higher profits. But in the channel relationships led by retailers, it is at a subordinate position and then the worst. Conclusion 2 can be obtained easily by comparing (17), (30), (38), and (42).

Conclusion 3. Among the coordination game, the noncoordination static game, Stackelberg game led by manufacturers, and Stackelberg game led by $n$ retailers, the manufacturer's optimal brand investment meets

$$
B_{M}^{\mathrm{RS} *}(t)<B_{M}^{N *}(t)<B_{M}^{\mathrm{MS} *}(t)<B_{M}^{T *}(t) .
$$

In Conclusion 3, although the manufacturer's brand investment is a function of time, we found optimal brand investment in the four cases has nothing to do with the time; all are constant. Furthermore, comparing the goodwill of the manufacturer, observing (19), (31), (39), and (43), we will find that the optimal reputation expressions of the four conditions have completely symmetrical structure. So, for comparing them, we only need to compare the coefficient; we can obtain Conclusion 4 below.

Conclusion 4. Among the noncoordination static game, Stackelberg game led by manufacturer, and Stackelberg game led by $n$ retailers, the manufacturer's optimal reputation at time $t$ meets

$$
G^{\mathrm{RS} *}(t)<G^{N *}(t)<G^{\mathrm{MS} *}(t)<G^{T *}(t) ;
$$

when $t \rightarrow+\infty$, the steady state meets

$$
G^{\mathrm{RS} *}(+\infty)<G^{N *}(+\infty)<G^{\mathrm{MS} *}(+\infty)<G^{T *}(+\infty) .
$$

Conclusion 4 shows that the reputation of the four kinds of channel relationship increase or decrease as time; we need to analyze the positive and negative of the coefficient of $e^{\delta t}$ in the expression. But in either case they will converge to their steady state. And from the inequality relation we can see that its reputation is maximum during channel integration.

Then, we analyze $n$ retailers' optimal decision relationship, and we can find Conclusion 5.

Conclusion 5. Among the noncoordination static game, Stackelberg game led by manufacturer, and Stackelberg game led by $n$ retailers, the retailer's optimal margins profit meet

$$
m_{i}^{N *}(t)<m_{i}^{\mathrm{MS} *}(t)<m_{i}^{\mathrm{RS} *}(t), \quad i=1,2, \ldots, n .
$$

For comparing the retailers' optimal investment, let $B_{i}^{*}(t) \triangleq g(\cdot)\left(a^{2} / b c_{i}\right) \sqrt{G^{*}(t)}$; when $G^{*}(t)$ meets $G^{\mathrm{RS} *}(t)<$ $G^{N *}(t)<G^{\mathrm{MS} *}(t)<G^{T *}(t)$, corresponding coefficient $g(\cdot)$ does not meet the corresponding relationship. Pradeep and Jain $a_{i}=1, r=0.1$ in [25]. Guiomar and Taboubi took $\delta=0.5, G_{0}=1$ in [29]. In this paper, we take $a=b=1$, $c_{M}=c_{i}=1, r=0.5, \delta=1, G_{0}=1, n=10, B_{i}^{\mathrm{RS} *}(t), B_{i}^{N *}(t)$, $B_{i}^{\mathrm{MS} *}(t), B_{i}^{T *}(t)$ as follows:

$$
\begin{aligned}
B_{i}^{\mathrm{RS} *}(t) & =\frac{1}{8} \sqrt{\frac{91}{96} e^{-t}+\frac{5}{96}}, \quad B_{i}^{N *}(t)=\frac{1}{9} \sqrt{\frac{223}{243} e^{-t}+\frac{20}{243}}, \\
B_{i}^{\mathrm{MS} *}(t) & =\frac{9}{64} \sqrt{\frac{467}{512} e^{-t}+\frac{45}{512}}, \quad B_{i}^{T *}(t)=\frac{1}{4} \sqrt{\frac{19}{24} e^{-t}+\frac{5}{24}} .
\end{aligned}
$$

We can see that $B_{i}^{T *}(t)>B_{i}^{\mathrm{MS} *}(t)>B_{i}^{\mathrm{RS} *}(t), B_{i}^{T *}(t)>$ $B_{i}^{\mathrm{MS} *}(t)>B_{i}^{N *}(t)$, but the relationship between $B_{i}^{\mathrm{RS} *}(t)$ and $B_{i}^{N *}(t)$ has a tipping point $t^{0}$. When $0 \leq t<t^{0}$, it holds that $B_{i}^{\mathrm{RS} *}(t)>B_{i}^{N *}(t)$; when $t^{0}<t<+\infty$, it holds that $B_{i}^{\mathrm{RS} *}(t)<$ $B_{i}^{N *}(t)$; when $t=t^{0}$, it holds that $B_{i}^{\mathrm{RS} *}(t)=B_{i}^{N *}(t)$. It is easy to get $t^{0}=\ln (17.2)$. Therefore, there is Conclusion 6 .

Conclusion 6. Among the coordination game, noncoordination static game, Stackelberg game led by manufacturers, and Stackelberg game led by $n$ retailers, the retailer's optimal marketing investment meets

(1) $B_{i}^{T *}(t)>B_{i}^{\mathrm{MS} *}(t)>B_{i}^{\mathrm{RS} *}(t), B_{i}^{T *}(t)>B_{i}^{\mathrm{MS} *}(t)>$ $B_{i}^{N *}(t)$;

(2) when $0 \leq t<\ln (17.2)$, it holds that $B_{i}^{\mathrm{RS} *}(t)>B_{i}^{N *}(t)$, when $\ln (17.2) \leq t<+\infty$, it holds that $B_{i}^{\mathrm{RS} *}(t)<$ $B_{i}^{N *}(t)$, and when $t=\ln (17.2)$, it holds that $B_{i}^{\mathrm{RS} *}(t)=$ $B_{i}^{N *}(t)$.

\subsection{Comparative Analysis of Optimal Profit of Channel Mem-} bers. In Section 4, when calculating the optimal decision variables, there was no calculation of the optimal profit of channel members, mainly because the specific values of constant $a, b, c_{M}, c_{i}, r, \delta, G_{0}, n$ were not given. Because the constant values do not affect the conclusion, Chen et al. take $a_{i}=1, r=0.1$ in [24]; Guiomar and Taboubi take $\delta_{i}=0.5$, $G_{0}=1$ in [29]. In this paper, $a=b=1 . c_{M}=c_{i}=1$, $r=0.5, \delta=1, G_{0}=1, n=10$, and it can be integral to calculate the optimal profit of channel members in four kinds of conditions; see Table 1 (calculation process slightly).

From Table 1, the following results hold.

Conclusion 7. Among the coordination game, noncoordination static game, Stackelberg game led by manufacturer, and Stackelberg game led by $n$ retailers, the optimal profits meet

(1) $\pi_{M}^{N *}>\sum_{1}^{n} \pi_{i}^{N *}, \pi_{M}^{\mathrm{MS} *}>\sum_{1}^{n} \pi_{i}^{\mathrm{MS} *}, \pi_{M}^{\mathrm{RS} *}<\sum_{1}^{n} \pi_{i}^{\mathrm{RS} *}$;

(2) channel total profits meets $\pi_{\text {total }}^{T *}>\pi_{\text {total }}^{\mathrm{MS} *}>\pi_{\text {total }}^{N *}>$ $\pi_{\text {total }}^{\mathrm{RS} *}$ 
TABLE 1: The optimal profit of 4 channel game relations.

\begin{tabular}{lcccc}
\hline & $\begin{array}{c}\text { Channel } \\
\text { integration }(T)\end{array}$ & $\begin{array}{c}\text { Static } \\
\text { game }(N)\end{array}$ & $\begin{array}{c}\text { Stackelberg game led } \\
\text { by manufacturers (MS) }\end{array}$ & $\begin{array}{c}\text { Stackelberg game led } \\
\text { by retailers (RS) }\end{array}$ \\
\hline Manufacturers' profits & & 0.089 & 0.0956 & 0.0548 \\
The $i$ th retailer's profits & & 0.00479 & 0.00775 & 0.00575 \\
Retailers total profits & & 0.0479 & 0.0775 & 0.0575 \\
Channel total profits & 0.2517 & 0.1369 & 0.1731 & 0.1123 \\
\hline
\end{tabular}

(3) for manufacturers $\pi_{M}^{\mathrm{MS} *}>\pi_{M}^{N *}>\pi_{M}^{\mathrm{RS} *}$;

(4) for retailers $\pi_{i}^{\mathrm{MS} *}>\pi_{i}^{\mathrm{N} *}>\pi_{i}^{\mathrm{RS} *}$.

In Conclusion 7 (1), we can find that in a noncoordination static game and in a Stackelberg game led by manufacturer, the profits of manufacturer are greater than the profits in the Stackelberg game led by $n$ retailers; while in a Stackelberg game led by retailers, the profits of manufacturer are less than the profits in a Stackelberg game led by $n$ retailers. And (2) shows that the maximum channel total profit can be gained when the channel is integrated, which is the pareto optimal state. At the same time, we also found that the channel total profits are the smallest when retailers dominate. From (3) and (4), while retailers can dominate the whole channel, the optimal profit to each retailer is not optimal.

\section{Conclusion}

This paper studies the optimal decision problems of distribution channel of one manufacturer and $n$ retailers. Only from the perspective of channel types, the models in this paper are the promotion of Xu et al. [6], Martín-Herrán and Taboubi [27], and Jørgensen and Zaccour [26]. This paper sets up four game models including the coordination game, noncoordination static game, Stackelberg game led by manufacturers, and Stackelberg game led by $n$ retailers. Results show that, for consumers, they hope that channel is integration or channel partners because of the lowest price. When $n$ retailers dominate the channel, retailers have voice and they will set higher retail prices to gain more profit; when the manufacturer is a leading enterprise, he has a certain discourse and he will naturally improve its marginal profit in order to obtain higher profits. But in the channel relationships led by retailers, it is at a subordinate position, then the worst. Although the manufacturer's brand investment is a function of time, we find that optimal brand investment in the four cases has nothing to do with the time, all are constant. Intuitively, a product brand investment should be increasing over time, but the rate of increasement is slower and slower, reaching a steady state value, which may be related to model building. It can be seen that in a noncoordination static game and in a Stackelberg game led by manufacturer, the profits of manufacturer are greater than the profits in the Stackelberg game led by $n$ retailers; while in a Stackelberg game led by retailers, the profits of manufacturer are less than the profits in a Stackelberg game led by $n$ retailers. And the maximum channel total profit can be gained when the channel is integrated, which is the pareto optimal state. At the same time, we also found that the channel total profits is the smallest when retailers dominate. That is to say, while retailers can dominate the whole channel, the optimal profit to each retailer is not optimal.

Some problems in this paper need studying continually, for example,

(1) in modeling, the status of $n$ retailers is equal, but in practice a fraction of retailers may be in a dominant position, as in a consumer market, Wal-Mart, and Carrefour, a number of other smaller retailers are a subordinate position;

(2) this paper uses the demand function $q_{i}(t)=B_{i}(t)[a-$ $\left.b p_{i}(t)\right] \sqrt{G(t)}$. Currently demand function is in a variety of forms and different expressions may differ, so classification research is needed;

(3) channel structures also need generalizing, such as $n$ manufacturers and $n$ retailers. However, mathematics model may be very complex.

\section{Conflict of Interests}

The authors declare that there is no conflict of interests regarding the publication of this paper.

\section{Acknowledgments}

The authors are particularly grateful to the associate editor and reviewers for thoughtful, valuable discussions and suggestions. The authors thank the financial support by Humanities and Social Science Project of Ministry of Education of China (14XJCZH001), Soft Science Research Project of Sichuan Province (2014ZR0027), Philosophy and Social Science Projects in Sichuan Province (SC14A030), and the Fundamental Research Funds for the Central Universities (JBK1507114, JBK130401), One of the authors also thank their students Huan Zhou and Weida Zhou's contribution to this paper.

\section{References}

[1] R. Desiraju and S. Moorthy, "Managing a distribution channel under asymmetric information with performance requirements," Management Science, vol. 43, no. 12, pp. 1628-1644, 1997.

[2] H. Baligh and L. E. Richartz, Vertical Market Structures, Allyn and Bacon, Boston, Mass, USA, 1967. 
[3] T. W. McGuire and R. Staelin, "Channel efficiency, incentive compatibility, transfer pricing and market structure: an equilibrium analysis of channel relationships," in Research in Marketing, L. P. Bucklin and J. M. Carman, Eds., vol. 8, JAI Press, Greenwich, Conn, USA, 1986.

[4] A. P. Jeul and S. M. Shugan, "Managing channel profits," Marketing Science, vol. 2, pp. 239-272, 1983.

[5] A. T. Coughlan, "Competition and cooperation in marketing channel choice: theory and application," Marketing Science, vol. 4, pp. 110-129, 1985.

[6] M. L. Xu, Q. Wang, and L. H. Ouyang, "Coordinating contracts for two-stage fashion supply chain with risk-averse retailer and price-dependent demand," Mathematical Problems in Engineering, vol. 2013, Article ID 259164, 12 pages, 2013.

[7] C. Ding, K. H. Wang, and R. Ran, "Marketing channel coordination mechanism based on fairness preference," Journal of Management Sciences in China, vol. 16, pp. 80-94, 2013.

[8] C. Ding, K. H. Wang, and S. Y. Lai, "Channel coordination mechanism with retailer having fairness preference-an improved quantity discount mechanism," Journal of Industrial and Management Optimization, vol. 9, pp. 967-982, 2013.

[9] C. Ding, K. H. Wang, and X. Y. Huang, "Channels coordination game model based on result fairness preference and reciprocal fairness preference: a behavior game forecasting and analysis method," Journal of Applied Mathematics, vol. 2014, Article ID 321958, 11 pages, 2014.

[10] N. Altintas, F. Erhun, and S. Tayur, "Quantity discounts under demand uncertainty," Management Science, vol. 54, no. 4, pp. 777-792, 2008.

[11] W. Song, R. Wang, Y. Fu, and X. Peng, "Consumer choice, firm performance and channel coordination in a dual-channel distribution system," American Journal of Operations Research, vol. 4, no. 4, pp. 217-227, 2014.

[12] L. Wang, H. Qu, S. Liu, and C. Chen, "Optimizing the joint replenishment and channel coordination problem under supply chain environment using a simple and effective differential evolution algorithm," Discrete Dynamics in Nature and Society, vol. 2014, Article ID 709856, 12 pages, 2014.

[13] H. F. Zhao, B. Lin, W. Q. Mao, and Y. Ye, "Differential game analyses of logistics service supply chain coordination by cost sharing contract," Journal of Applied Mathematics, vol. 2014, Article ID 842409, 10 pages, 2014.

[14] T. Li, S. P. Sethi, and X. He, "Dynamic pricing, production, and channel coordination with stochastic learning," Production and Operations Management, vol. 121, pp. 245-275, 2015.

[15] X. Chen, G. Hao, and L. Li, "Channel coordination with a lossaverse retailer and option contracts," International Journal of Production Economics, vol. 150, pp. 52-57, 2014.

[16] X. Wang and S. Webster, "Channel coordination for a supply chain with a risk-neutral manufacturer and a loss-averse retailer," Decision Sciences, vol. 38, no. 3, pp. 361-389, 2007.

[17] L. Jiang, Y. Wang, and X. Yan, "Decision and coordination in a competing retail channel involving a third-party logistics provider," Computers and Industrial Engineering, vol. 76, pp. 109-121, 2014.

[18] S. S. Yin, T. Nishi, and I. E. Grossmann, "Optimal quantity discount coordination for supply chain optimization with one manufacturer and multiple suppliers under demand uncertainty," The International Journal of Advanced Manufacturing Technology, vol. 76, no. 5, pp. 1173-1184, 2015.

[19] L. Rajiv, "Improving channel coordination through franchising," Marketing Science, vol. 9, pp. 299-318, 1990.
[20] F. B. Benjamin and R. L. Tracy, "Optimal retail contracts with asymmetric information and moral hazard," Rand Journal of Economics, vol. 5, pp. 284-296, 1994.

[21] D. Zissis, G. Ioannou, and A. Burnetas, "Supply chain coordination under discrete information asymmetries and quantity discounts," Omega-International Journal of Management Science, vol. 53, pp. 21-29, 2015.

[22] D. T. Luo, W. J. Zhong, X. Q. Zhang, and H. C. Shen, "Side payment incentive of a decentralized supply chain mechanism," Journal of System Engineering Research, vol. 16, pp. 236-240, 2001.

[23] H. P. Tian, Y. J. Guo, and Y. D. Yang, "The principal agent problem of multi principals and the principal may cooperate in the distribution system," The Application of the Theory of System Engineering Methods, vol. 13, pp. 567-574, 2004.

[24] J. Chen, F. H. Wang, and C. P. Zhao, “The formation mechanism of the marketing channel alliance based on the information asymmetric game," Journal of Shanghai Jiao Tong University, vol. 39, pp. 357-366, 2005.

[25] K. C. Pradeep and D. Jain, "A dynamic model of channel member strategies for marketing expenditures," Marketing Science, vol. 11, pp. 168-188, 1992.

[26] S. Jørgensen and G. Zaccour, "Channel coordination over time: incentive equilibria and credibility," Journal of Economic Dynamics and Control, vol. 27, pp. 801-822, 2003.

[27] G. Martín-Herrán and S. Taboubi, "Stackelberg leadership in a marketing channel," International Game Theory Review, vol. 3, no. 1, pp. 13-26, 2001.

[28] G. Martín-Herrán and S. Taboubi, "Price coordination in distribution channels: a dynamic perspective," European Journal of Operational Research, vol. 240, no. 2, pp. 401-414, 2015.

[29] G. Martín-Herrán and S. Taboubi, "Shelf-space allocation and advertising decisions in the marketing channel:a differential game approach," International Game Theory Review, vol. 7, pp. 313-330, 2005.

[30] Q. R. Pan, Economic Management Dynamic System Optimization, vol. 3, University of Science and Technology of China Press, 1993.

[31] J. Z. Yuan, Y. Zhang, and Y. Tong, The Economic Foundation of Control Theory and Its Applications, Higher Education Press, Beijing, China, 2004.

[32] Z. Y. Jiang, Dynamic Optimization, The Commercial Press, Beijing, China, 2003. 


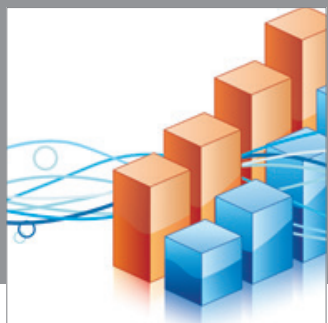

Advances in

Operations Research

mansans

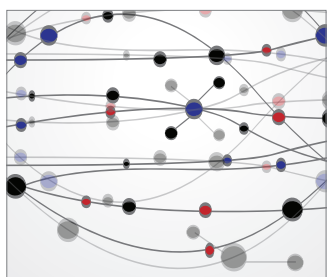

The Scientific World Journal
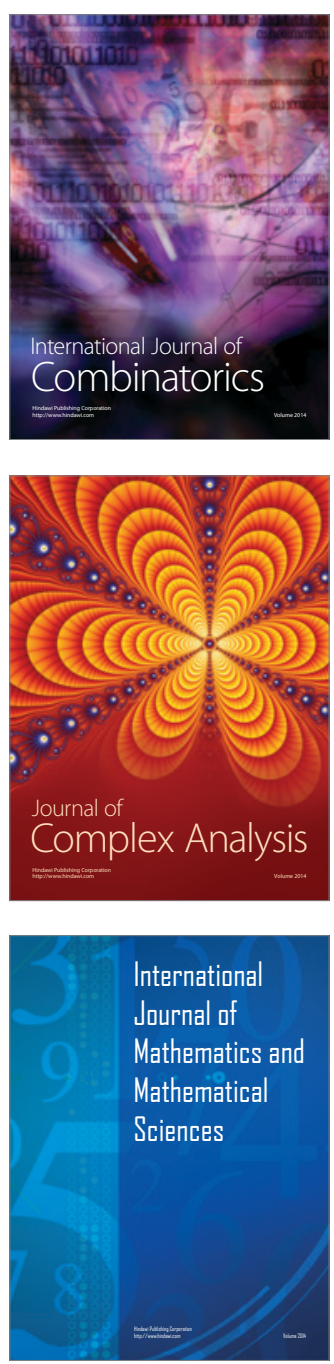
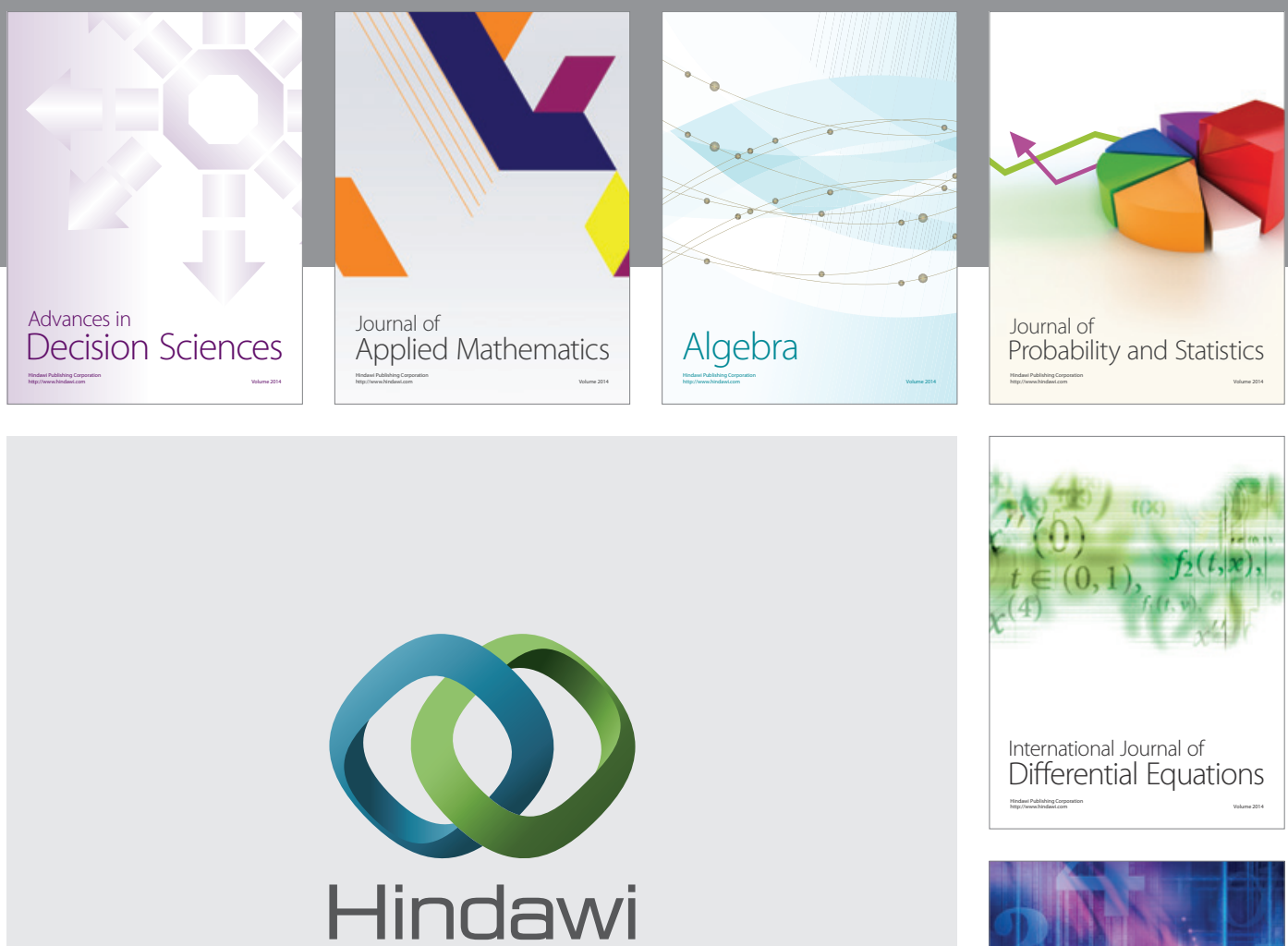

Submit your manuscripts at http://www.hindawi.com
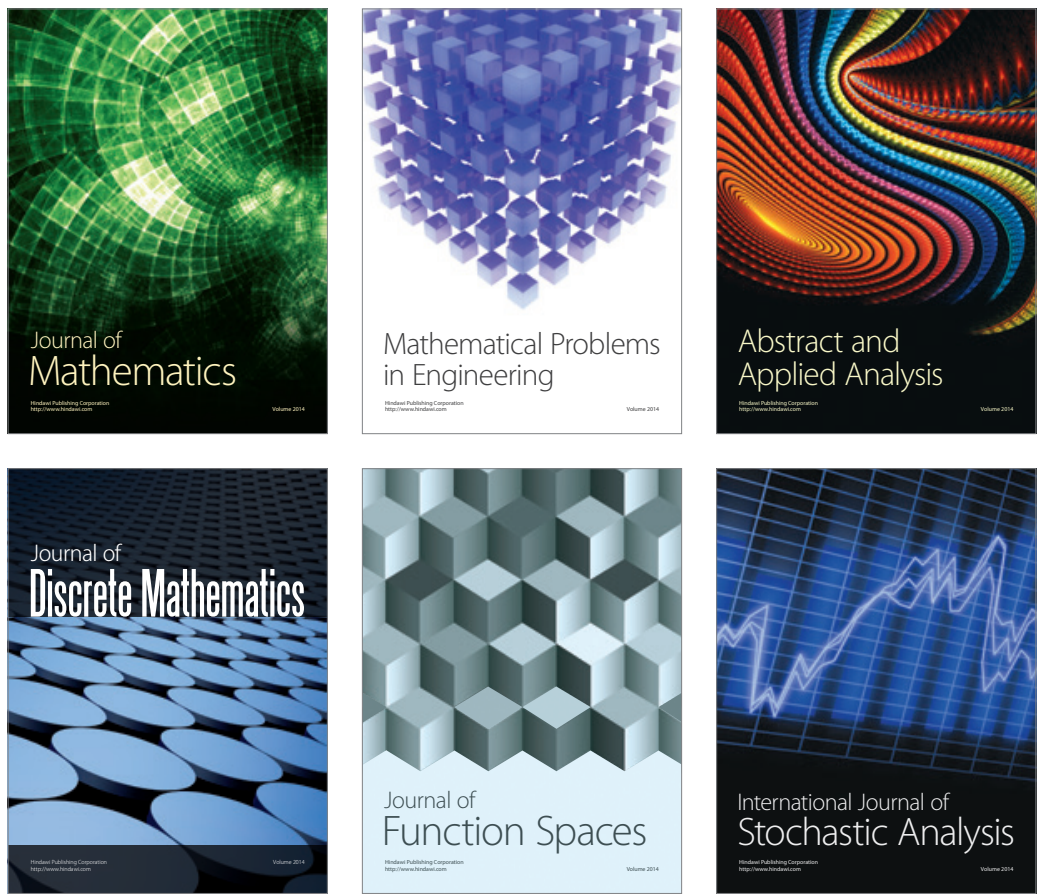

Journal of

Function Spaces

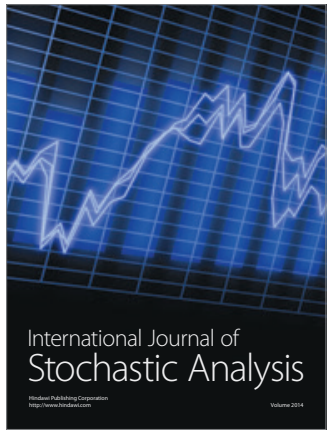

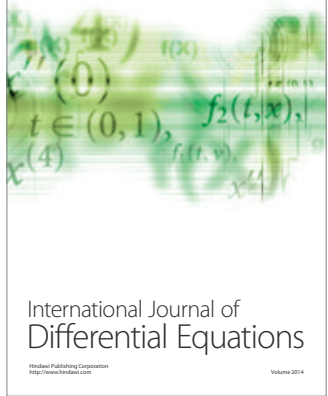
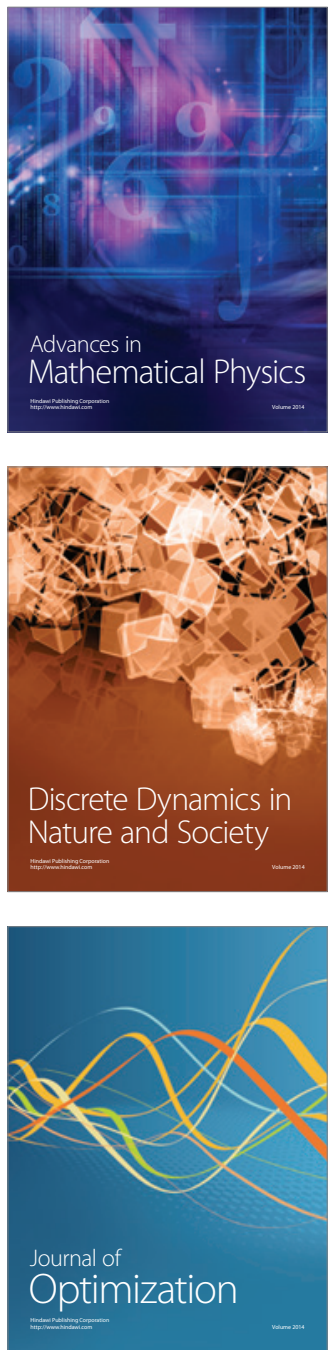